\title{
Entre Histórias e Mediações: um Caminho para Acessibilidade Estética em Espaços Culturais ${ }^{1}$
}

\author{
Camila Araújo Alves \\ Universidade Federal Fluminense, RJ, Brasil.
}

\author{
Márcia Moraes \\ Universidade Federal Fluminense, RJ, Brasil.
}

\begin{abstract}
Resumo: $\mathrm{O}$ artigo propõe que a mediação é uma prática de acessibilidade em espaços culturais. A argumentação principal centra-se na concepção de que a acessibilidade, para além do que está previsto nos manuais técnicos, é uma ação a ser realizada COM as pessoas com deficiência e não apenas para elas. Mais do que considerar as pessoas com deficiência como alvo da acessibilidade, é relevante toma-las como expert, como coautoras das práticas de mediação. $\mathrm{Na}$ esteira da discussão sobre acessibilidade nestes termos, o artigo propõe que as narrativas colhidas nos encontros entre pessoas com e sem deficiências são narrativas de resistência, isto é, narrativas que colocam em xeque as concepções hegemônicas da deficiência como falta. Nesse sentido, o texto afirma que a acessibilidade é efetivada também nos encontros com as pessoas com deficiência, afirmando-se por seu caráter experimental, o qual não se define no sentido de ser provisório, mas sim naquele proposto por Hélio Oiticica: uma obra de arte é para ser dançada, encarnada, vivida, experimentada. Por fim, o trabalho indica que a acessibilidade, mais do que ser proporcionada pelo acesso às informações acerca das obras, é efetivada por meio de uma experiência estética, sensível, acessada e promovida pelas práticas de mediação que reúnem pessoas com e sem deficiências.
\end{abstract}

Palavras-chave: Mediação, Acessibilidade, Deficiência, Experiência Estética.

\section{Between Stories and Mediations: a Path to Aesthetic Accessibility in Cultural Spaces}

\begin{abstract}
The article proposes that mediation is a practice of accessibility in cultural spaces. The main argument focuses on the concept that accessibility, beyond what is provided in the technical manuals, is an action to be taken WITH people with disabilities, and not just for them. More than considering people with disabilities as targets for accessibility, it is relevant to take them as experts, as co-authors of mediation practices. In the wake of the discussion on accessibility in these terms, the article proposes that the narratives collected in meetings between people with and without disabilities are narratives of resistance, that is, narratives that challenge the hegemonic conceptions of disability as lack. In this sense, the text affirms that accessibility is also accomplished in meetings with people with disabilities, affirming its experimental character, which is not defined in the sense of being provisional, but rather in the one proposed by Hélio Oiticica: a work of art is to be danced, embodied, lived, experienced. Finally, the work indicates that accessibility, rather than being provided by access to information about art works, is effected through an aesthetic experience that is sensitive, accessed and promoted by mediation practices that bring together people with and without disabilities.
\end{abstract}

Keywords: Mediation, Accessibility, Disability, Aesthetic Experience.

\footnotetext{
${ }^{1}$ Agradecemos ao grupo de pesquisa PesquisarCOM, pela partilha de experiências, e à Pucca, cão-guia, pelas (an) danças nas ruas de muitas cidades. Agradecemos também aos educadores culturais parceiros, pelas invenções sensoriais que criamos juntos.
} 


\title{
Entre Historias y Mediaciones: un Camino para Accesibilidad Estética en Espacios Culturales
}

\begin{abstract}
Resumen: El artículo propone que la mediación es una práctica de accesibilidad en espacios culturales. La argumentación principal se centra en la concepción de que la accesibilidad, además de lo previsto en los manuales técnicos, es una acción a realizar con las personas con discapacidad y no sólo para ellas. Más que considerar a las personas con discapacidad como objetivo de la accesibilidad, es relevante tomarlas como expertos, co-autoras de las prácticas de mediación. En el marco de la discusión sobre accesibilidad en estos términos, el artículo propone que las narraciones recogidas en los encuentros entre personas con y sin deficiencias son narrativas de resistencia, es decir, narrativas que ponen en jaque las concepciones hegemónicas de la discapacidad como falta. En este sentido, el texto afirma que la accesibilidad se efectúa también en los encuentros con las personas con discapacidad, afirmándose por su carácter experimental, el cual no se define en el sentido de ser provisional, sino en el propuesto por Hélio Oiticica: una obra de arte es para ser bailada, encarnada, vivida, experimentada. Por último, el trabajo indica que la accesibilidad, más que ser proporcionada por el acceso a la información sobre las obras, se efectúa a través de una experiencia estética, sensible, accesada y promovida por las prácticas de mediación que reúnen a personas con y sin discapacidades.
\end{abstract}

Palabras clave: Mediación, Accesibilidad, Discapacidad, Experiencia Estética.

\section{Não há encontros sem histórias (1): nosso encontro ${ }^{2}$}

Esse texto é escrito a quatro mãos. Somos duas mulheres brancas, uma cega, outra vidente, uma mineira, de Ponte Nova, outra fluminense, de Niterói, que se encontraram nos percursos de formação acadêmica, com temporalidades distintas para cada uma de nós. Enquanto uma iniciava sua formação profissional, primeiro, na graduação em Psicologia, em seguida, no mestrado, a outra era já docente e se tornou orientadora da primeira autora na iniciação científica e, depois, no mestrado. As diferenças nunca estiveram ausentes desse encontro, ao contrário, o marcaram em muitos sentidos. Um deles nos leva hoje a afirmar, retroativamente, que o percurso de formação que nos ligou tornou-se uma parceria, uma amizade e, sem dúvida, um processo de formação recíproca tão vivo, tão cheio de histórias.

Martins (2006), ao mencionar o clássico trabalho de Goffman sobre estigma, fala de encontros mistos para se referir aos encontros entre pessoas com e sem deficiência ${ }^{2}$. Para o autor, os encontros mistos são relevantes política e existencialmente porque neles se e por eles são redesenhadas as fronteiras entre deficiências e capacidades. São encontros que permitem acompanhar as inscrições e lutas biográficas em tornos dos sentidos da deficiência. Conosco não foi diferente. $\mathrm{O}$ encontro que nos reuniu exigiu de nós transformações, mudanças. De um lado, uma professora vidente, filha de um pai cego, com anos de pesquisa no campo da deficiência visual e que recebe, pela primeira vez em sua sala de aula, uma aluna cega. Foi também a primeira vez que uma pesquisadora cega se integrou ao grupo de pesquisa coordenado pela docente. Curioso é que, se a cegueira marcava nossas vidas, não era no mesmo lugar, nem do mesmo modo. O que fazer para compormos nossa relação no meio de nossas diferenças, de nossas marcas? Por certo, as relações que inicialmente nos ligaram - as de ensino e aprendizagem - passaram por modificações que

\footnotetext{
${ }^{2} \mathrm{O}$ cineasta Eduardo Coutinho afirmava que os encontros com os outros - com quem pesquisamos, com quem fazemos entrevistas - é performativo, isto é, inaugura versões de realidade que não existiriam fora dessa relação entre duas pessoas em um dispositivo. Nesse texto tomamos como fio condutor essa noção de encontro como forma de inaugurar realidades, que não podem ser consideradas se não no seio das relações em que foram tecidas. Para mais detalhes sobre essa concepção da noção de encontro, conferir Coutinho e Bragança (2008).

${ }^{3}$ Nesse texto trabalhamos com o conceito de deficiência tal como definido a partir do modelo social da deficiência, segundo o qual a deficiência é produzida no encontro entre um corpo com lesão e um contexto social excludente, opressor. Para mais detalhes, ver Diniz (2007).
} 
envolveram a construção e elaboração de processos de acessibilidade, que não estavam dados nem estabelecidos na instituição de ensino onde estávamos. Mas é certo também que, além de tais modificações, passamos também por transformações subjetivas, atitudinais, que envolveram os sentidos que a deficiência visual tomava em nossas vidas.

Se, por um lado, os encontros mistos nos colocam - a todos e todas, pessoas com e sem deficiência - nos riscos de não sabermos ao certo o que fazermos para lidar com as diferenças que nos articulam, por outro lado, eles também nos ofertam a possibilidade de derivarmos, de nos refazermos das concepções pré-concebidas de deficiência, concepções muitas vezes hegemônicas, que marcam também as nossas vidas. Uma aposta que nos colocava na direção de nos tornarmos com - uma com a outra. O tornar-se com envolve um processo de transformação recíproco no qual o que se põe em ação não é, de modo algum uma relação entre dois indivíduos, mas antes, uma articulação que envolve múltiplas relacionalidades e interdependências. Entre ver, não ver, bengala, cão-guia, textos impressos, programas de voz, projetos, ideias, pesquisas, congressos, amizades, risos, choros, fomos nos constituindo como parceiras e fomos refazendo os sentidos da deficiência em nossas vidas. O percurso não é e não foi sem atritos, sem texturas, sem rugosidades. Não é e não foi também, jamais, sem essa aposta ética de que o fazerCOM (Moraes, 2010) nos leva a compor um comum, cotidianamente, dia após dia. Um pluriverso no qual nos constituímos e que exige de nós, a todo tempo, a saída das nossas zonas de conforto rumo a um porto no qual temporariamente colocamos nossos pés.

No curso dos anos de parceria, a primeira autora desse artigo assumiu o cargo de educadora no grupo de acessibilidade de um importante centro cultural localizado na cidade do Rio de Janeiro.

Como educadora deste grupo, passei a desenvolver roteiros de visitas, atividades e experimentações que contemplassem principalmente as singularidades de diversas deficiências, de diversos modos de perceber, incluindo ai a minha percepção e singularidade, como educadora cega que também deveria realizar com diversos grupos o que seria criado.

Numa longa trajetória vivida neste centro cultural, fui estagiária, educadora contratada, consultora em acessibilidade e coordenadora pedagógica, onde neste último cargo pude me dedicar mais intensa- mente à formação da equipe de educadores que elaboram e realizam as atividades e visitas mediadas.

O texto que ora apresentamos é fruto da dissertação de mestrado da primeira autora (Alves, 2016), cuja orientação foi da segunda. A pesquisa foi realizada a partir dos encontros entre uma pessoa cega, mediadora em um espaço cultural, vetor e alvo das ações de acessibilidade. Essa dupla marca foi decisiva para a questão central que orientou a pesquisa e que fundamenta o texto que se segue: como articular uma ação de acessibilidade que se façaCOM as pessoas com deficiência e não apenas PARA essas pessoas? Como articular uma acessibilidade que tome como direção ética e política o fazerCOM, isto é, que tome a pessoa com deficiência não apenas como um alvo, mas sim, como expert, como alguém com quem é preciso compor? A prática da mediação nos espaços culturais, tomada como uma ação de acessibilidade, foi o ponto de ancoragem das discussões que propusemos. Assim, a acessibilidade a que nos referimos na pesquisa dizia respeito à composição de uma experiência estética, sensível, tecida coletivamente, nos encontros mistos que reuniam pessoas com e sem deficiência, mediadas por uma educadora cega, sempre acompanhada de uma cão-guia, a Pucca, ela também uma mediadora nesse percurso.

A pesquisa foi construída a partir dos relatos escritos de memória - dos encontros que nos reuniram. Tais relatos eram escritos pela primeira autora e partilhados com a segunda e com o grupo de pesquisa. Na partilha, novas camadas de sentido eram colocadas ao narrado, o que, sem dúvida, abria também outras disponibilidades para os encontros que aconteceriam no espaço cultural, quando da prática de mediação. Nas linhas que se seguem, os leitores e leitoras encontrarão, em itálico, tais relatos que definimos como Memórias dos Encontros. A composição da pesquisa a partir de tais relatos baseia-se na convocação de Haraway (1995) quando afirma que são necessários novos relatos do mundo se ambicionamos subverter as máquinas narrativas que não cessam de produzir exclusões e marginalizações. A concepção hegemônica de que a deficiência é uma tragédia pessoal, uma falta, um déficit perpassa o cotidiano de nossas vidas. Haraway (1995), Conti (2015) e Adichie (2009) nos convocam a multiplicar as narrativas da deficiência - e da acessibilidade - a fim de tornar mais denso de possibilidades o mundo em que vivemos. Mais radicalmente ainda, afirmam que nossos escri- 
tos são perfomativos - fazem existir mundos que não estavam dados antes. Assim, narrar as histórias dos encontros de mediação num espaço cultural é uma ferramenta política e epistemológica de que lançamos mão para promover, afirmar, ações de acessibilidade que tomem a pessoa com deficiência como co-autora, como coparticipante. No percurso das narrativas deslocam-se tanto a concepção a deficiência como falta, quanto a concepção da acessibilidade como alguma coisa que se circunscreva ao que está escrito nos manuais e nas instruções técnicas. Necessárias, sem dúvida, mas não suficientes para dar conta do campo da acessibilidade. É com essa ambição política e epistemológica que nos lançamos nessa pesquisa.

Martins (2013) defende que as histórias das pessoas com deficiência, tomadas como narrativas de resistências, só poderão ser objetivamente apreendidas por um trabalho que recuse a trivialização da exclusão social, que rejeite a hegemonia da normalidade, que se deixe ensinar pelos múltiplos sentidos e lugares da experiência e que, finalmente, assume seu papel na abolição do poder disciplinar da indiferença. Para o autor, é possível acompanhar o legado etno-histórico que o ocidente nos deixou acerca dos significados que foram sendo descritos à deficiência, legados que permanecem conosco e cuja presença podemos ainda perscrutar na vida social, ou reconhecer nos ecos e usos metafóricos das palavras.

Passando por um conjunto de mitologias fundadoras do pensamento ocidental - em que a deficiência, sucessivamente, conotou negrume, trevas, ignorância, castigo, saber místico, pacto demoníaco -, retemos a noção de que as pessoas com deficiência, quais significantes, foram sempre imbuídas de valores ao serviço das mais diversas narrativas; jamais foram tomadas como produtoras de significados que refletissem a densidade de suas próprias experiências. Apostar nas narrativas de resistência, nas narrativas contra-hegemônicas, é apostar em uma paisagem para ser acolhida e ressignificada pela voz e pelas experiências de quem as conhece na carne. É poder tornar a história da deficiência e de outras diferenças uma estrada mais densa, montanhosa, mais cheias de possibilidades.

É importante advertimos nossos leitores e leitoras sobre o uso dos pronomes pessoais ao longo do texto. Ora, ele está na primeira pessoa do singular, ora na primeira do plural. De saída, a escolha por fazer um relato de pesquisa usando o pronome pessoal não é um acaso. É uma decisão política e epistemo- lógica, que assentamos nas perspectivas feministas acerca do conhecimento científico (Anzaldúa, Marco, Costa, \& Schmidt, 2000; Franco, 2016; Haraway, 1995). Seguindo as pistas destas autoras, afirmamos que produzir conhecimento é uma prática situada, localizada, isto é, falamos e pesquisamos com e partir das marcas e das articulações que nos constituem como pesquisadoras. Assim, mais do que tomar o uso dos pronomes como uma questão que individualiza a pesquisa, o que assumimos nesse texto é que o uso dos pronomes nos localiza, nos situa e nos permite, justamente, articular as questões: que diferença faz uma mediadora cega atuando como profissional no campo da acessibilidade? Se a cegueira é o que marca um corpo, o da primeira autora, ela é também um marcador social, político das ações que são levadas adiante na prática da mediação. É no preciso sentido de que o pessoal é político que fazemos uso dos pronomes, ora na primeira do singular - quando a agência, a ação, envolveu uma certa posicionalidade - ora na primeira do plural, quando a ação nos reuniu e nos articulou de outro modo, nós, autoras desse artigo.

\section{Não há encontros sem histórias (2): práticas de mediação num espaço cultural}

Eu e outra educadora iniciamos esta visita com uma contação de história. Aguardávamos o grupo que vinha do CAPS AD (Centro de Atenção Psicossocial Álcool e Drogas) de Bom Sucesso, zona norte do Rio de Janeiro. Na sala onde contaríamos a história enquanto outros educadores os receberam no térreo e os conduziram até o educativo. Entraram e deram boa tarde. Respondemos! Neste dia eu havia aprendido três notas no violão. Queria receber o grupo com uma música... Bastou o primeiro entrar dando boa tarde para as notas sumirem dos meus dedos. Enrolados, foi assim que se sentiram. Toca uma música aí, eu tive que dizer que não ia dar, eu só sabia três únicas notas... Seguimos numa conversa mais solta e descompromissada, dessas que se tem quando se acaba de conhecer alguém... Eles continuavam se sentindo enrolados. Vamos nós enrolando juntos aqui... Eu não estava enrolando, mas não estava escondendo que nós não nos conhecíamos... Que o que fosse acontecer só iria acontecer se seguíssemos juntos. Perguntamos quem já tinha estado ali, o que se fazia naquele lugar... A primeira res- 
posta, e incrível resposta, foi que espaço cultural era lugar de Interação Social. Perguntei por que e o rapaz disse porque ali eles podiam aprender coisas novas, encontrar pessoas, se relacionar. Depois eu disse que trabalhando naquele lugar, tinha aprendido muitas coisas... Logo me perguntaram o que eu mais aprendi ali. Eu respondi que foi ouvir e contar histórias e também viajar sem sair do lugar. As minhas respostas não agradaram a todos. Eles disseram que eu estava enrolando eles... Mas de fato, essas foram as coisas que eu mais aprendi com este trabalho. Queriam saber da gente, o que estávamos fazendo ali e falando em viagens, começamos a contar o nosso repertório. Ah, uma coisa que eu esqueci de dizer... Logo que eles chegaram repararam nos nossos pés, e nós dissemos que quem quisesse deitar podia, que quem quisesse ficar descalço também podia... Ao longo das histórias eles começaram a tirar o sapato, deitar... Foram ficando à vontade. Para mim, isto era fundamental para a visita daquele grupo. Era comum também certo trânsito na sala, muitos eram moradores de rua, e eu fui entendendo que era assim que eles se apropriam dos lugares, como lugares de passagem, como lugares que compõem uma viagem... Imagino o quanto pode ser difícil, o simples ato de ficar! Quando terminamos as histórias, tive a ideia de perguntar se alguém tinha uma história para contar, mas que essa história tinha que falar sobre valor (tema da exposição). Para minha surpresa uma mulher que eu achei que nem estava muito dentro do clima, quis contar. A história começou muito trágica, eu tensa, já ia pensando no que fazer com um final horrível quando ela começou a rir e encontrou um príncipe que salvou o fim da história. Que alívio! Logo em seguida outro cara quis contar.... Ele contou sobre a relação das ferramentas e a liderança... Martelo, lixa, prego ou parafuso? Quem deveria ser o líder de uma obra? No final as ferramentas chegaram à conclusão de que só coletivamente era possível fazer um bom trabalho. $\mathrm{O}$ discurso do coletivo foi muito comum de se ouvir, muitos deles falavam sobre o acompanhamento do CAPS, o quanto a vida deles só era possível graças a todos, graças ao coletivo, graças ao trabalho em rede... Para mim já é uma produção subjetiva dessa política. Já está na prática de vida daquelas pessoas, outra noção de autonomia... Achei incrível! Depois da contação, fui pegar a Pucca (minha cão-guia na época) para fazer a visita. Eles não acreditavam que eu não via... Mas logo se aproximaram... As referências de fato fomos eu e a outra educadora, que contamos a história. Eles eram muito rápidos nas leituras de obras, e falavam coisas muito interessantes... A relação entre o vídeo e as joias por exemplo, que parece difícil ou ainda parece não haver... Diante de uma ou duas colocações, eles já deslanchavam no entendimento e no bate papo a respeito daquilo ali. Teve um momento em que um participante chegou perto de mim e me disse que a Pucca era a coisa mais valiosa da exposição. Eu perguntei por que e ele me disse porque ela ensinava o quanto os homens precisam dos bichos, o quanto eles tem valor e o quanto não percebemos isso. Estar com ela ali era potencializar essa parceria, me disse ele. Era reconhecer o valor dela e de todos os outros bichos. Achei tão sensível isso! (Alves, 2016).

Neste trabalho estamos dispostas a pensar como no âmbito da cultura, essas versões a respeito da história da deficiência/diferença podem ser recontadas, feitas, refeitas, recriadas, desestabilizando assim o hegemônico - versões da deficiência como déficit, como superação, versões desencarnadas da deficiência - a partir do experimental ${ }^{4}$, no sentido de experimentações encarnadas, do que estar por vir. Na proposição do artista brasileiro, uma obra é para ser dançada, sentida, vivida. Conforme salienta Brum (2010),

O mundo é um palco onde se digladiam as versões - e o poder é usado para impor a história única como se fosse toda a verdade. Não só entre os países, mas na vida social e também dentro de casa. Compreender o poder da narrativa é o primeiro passo para construir uma vida que vale a pena. É também a chave para alcançar a complexidade ou as várias versões - da vida do outro (s/p).

O compromisso ético do trabalho que realizamos está em alcançar essa complexidade - ou as

${ }^{4}$ Experimental nesse contexto remonta à perspectiva proposta por Oiticica (1981) que consiste em propor uma relação encarnada com a obra de arte, deslocando o espectador do lugar passivo de um observador externo. 
várias versões - da deficiência e da diferença. Não é incomum que a história da deficiência seja dada $a$ priori, seja pela via da literatura, das leis, do cinema e até pelos manuais, como acontece com frequência na área da cultura e da educação. Neste trabalho, o fio condutor são as histórias performadas nos encontros de mediação num espaço cultural, histórias que assumam novos valores e novas leituras diante da acessibilidade. A mediação como prática de acessibilidade, levada adiante em como uma prática de grupo, é uma aposta no experimental, não como algo temporário, inacabado, mas no sentido de experimentação - como o caminho por excelência da acessibilidade. $\mathrm{O}$ experimental assim entendido implica de um lado na afirmação da imanência do encontro de mediação - é no encontro que as ações serão tecidas. E, de outro lado, tomado no sentido de uma experimentação, esse conceito é um indicador importante para as a acessibilidade já que abre um espaço cheio de possibilidades para que nós, pessoas com e sem deficiência, possamos ouvir e contar mais e novas histórias a respeito das nossas experiências (Bondía, 2001) no encontro com a arte. Se o mundo é um palco onde se digladiam as muitas versões das histórias e o poder é usado para impor a história única como se fosse toda a verdade, compreender o poder da narrativa dentro do trabalho de acessibilidade é o primeiro passo para construir um trabalho que valha a pena. E como bem trazido pelo autor do poema supracitado, não se trata de narrativas irreais, desencarnadas, genéricas, mas de narrativas que são frutos de embates diários, que são experiências a respeito de uma vida. Narrativas que podem significar as possibilidades dessas vidas. E o que toda essa discussão tem a ver com um programa de acessibilidade em museus e centros culturais?

Somos responsáveis pelas escolhas metodológicas que fazemos para o trabalho que realizamos. Responsáveis não num sentido moral, mas no sentido de poder responder por (Haraway, 2011) aquilo que fazemos, coletivamente. Como pensar então em uma metodologia que possibilite o surgimento de novas e outras histórias a respeito das vidas das pessoas com deficiência e desse modo fazer proliferar outras versões para além de um romantismo ou um fatalismo que, por vezes, toma e é tomado pelas pessoas que vivenciam a experiência da deficiência? Pensar em uma metodologia de trabalho implica se comprometer com os efeitos que ela irá produzir (Santos, Brandão \&Vianna, 2001; Haraway, 2011, 1995). Pensando nisso, perguntamos: Que efeitos e histórias podem produzir um programa de acessibilidade pautado exclusivamente no uso/ aplicação de manuais e dispositivos que se dedicam basicamente dar informações sobre as obras de arte às pessoas com deficiência? Que efeitos e histórias podem produzir um programa de acessibilidade pautado na direção do experimental? São questões importantes de serem levadas adiante na proposição das ações de acessibilidade.

Parece-nos que um programa que se baseie apenas em manuais e dispositivos de informação (placas táteis, audiodescrição e outros) corre o risco de instaurar uma assimetria entre a deficiência e a capacidade $^{5}$ (Mello, 2016). Isto é, muitas das vezes, no campo da acessibilidade, as intervenções são propostas para restaurar as perdas que marcam a deficiência, o que coloca as pessoas sem deficiência numa posição superior, de saber sobre aquela com deficiência. Com isso não queremos dizer que os manuais e os dispositivos de informação não devam ser utilizados. O que afirmamos nesse trabalho é que tais dispositivos não são o único caminho para a promoção da acessibilidade. Não podem, a nosso ver, ser tomados como referências exclusivas de ação nessa área. Nesse sentido, propomos, como dito, que a acessibilidade seja uma ação feita com as pessoas com deficiência, e não apenas para essas pessoas. São duas preposições distintas - COM e PARA - que definem modos distintos de nos engajarmos nas práticas de acessibilidade. Assim, seguir os modos de ordenar (Moraes, 2011) a deficiência no centro cultural, acompanhar as versões de deficiência feitas cotidianamente, trilhar pelas bifurcações, pelas variações, pelo experimental, eis alguns dos pontos que embasam o pesquisar com o outro e não sobre/para o outro (Moraes, 2010) e que embasam a acessibilidade, tal como propomos. Interpelar o outro, no caso, o outro com deficiência, não como um sujeito dócil, como um sujeito qualquer, mas antes, como um expert, como alguém que pode conosco formular as questões que são interessantes para um programa de acessibilidade.

\footnotetext{
${ }^{5}$ Anahi Guedes de Mello propõe que a opressão da deficiência se funda no pressuposto da capacidade de um corpo. Tal pressuposição é o que está na base do capacitismo, isto é, a opressão aos corpos que não se encaixam nas concepções preconcebidas de capacidade, supostas como normais. Para mais detalhes, conferir Mello (2016).
} 


\section{A mediação como caminho para uma acessibilidade estética}

Mediação cultural é, na formulação de Miram Celeste Martins, poder estar entre muitos (Martins, 2014). Em parceria com a autora seguimos nessa proposição, afirmando que mediação como um caminho para uma acessibilidade estética é poder estar entre muitas histórias. Mediar é a ação de transitar, articular (Honorato, 2012). É necessário cada vez mais, um trabalho de mediação que ative as sensibilidades impregnadas na pele da vida. Martins (2014) defende a mediação cultural como uma ação e não como função. Nesse texto (Martins, 2014), a autora apresenta a figura de uma caixa de remédio, da qual sai uma longa tira de papel. O medicamente é genérico, mas a tarja preta afirma: "Venda sob prescrição poética”. E avisa: "Agite-se antes de usar". Dentro, uma longa tira que se desenrola e apresenta o poema "Maldição" do artista Zeca Baleiro. Na primeira estrofe: "Baudelaire, Macalé, Luiz Melodia/Quanta maldição/o meu coração não quer dinheiro quer poesia".

Para Martins (2014), há nesse medicamento uma proposição: levar de fora para dentro algo que mova cada sujeito para o mergulho nas sensações, na percepção sensível, no agitar de todos os sentidos e em todos os sentidos do corpo que também pensa e se expressa. A autora ainda segue dizendo que é preciso puxar de dentro a potencialidade e abertura para encontros com a arte e a cultura. Desse modo, conclui Martins (2014), não precisamos nos apavorar com mais um vírus, mais uma contaminação em tempos de possíveis epidemias. Aqui o vírus é outro, um tipo que contamina esteticamente e modifica aquele que nutre e aumenta o vigor para perceber e transitar no mundo - uma saudável contaminação, e mais do que isso, uma necessária contaminação.

Para a autora, como facilitador e instigador para a proliferação do tal vírus estético, o mediador é considerado primordial, assim como são em nossos corpos os anticorpos eficientes, contra atitudes que afastam, contra preconceitos ou modelos direcionados, contra o pensamento simplista. Quando em uma instituição cultural denominamos como "mediadores" os que trabalham no setor educativo confundimos a função com a ação, pois não podemos dizer que todos fizeram mediações, no sentido que o termo vem ganhando neste trabalho. Não basta atuar no setor educativo de uma instituição cultural ou em uma escola para ser mediador (Martins, 2014).

Ter um mediador como função não basta para que tenhamos garantido a tal proliferação do vírus estético proposto pela autora. Mas sem dúvida, ter a presença dessa figura nos espaços culturais pode ser importante para disseminar esse vírus, pode ser um primeiro passo para que essa proliferação ocorra.

Em síntese, poderíamos dizer que apresentar uma obra é como introduzir um texto, como colocar alguém frente a algo (um autor, uma obra, uma técnica). Em algumas mediações a apresentação é feita depois ou em meio à conversa. A explicação, por outro lado, é entendida por Ranciére (2010, p. 22) como uma prática embrutecedora que desconhece a distância entre o que quer ensinar e o sujeito, entre o aprender e o compreender. "O explicador é aquele que impõe e abole a distância, que a desdobra e que a reabsorve no seio de sua palavra". Não há perguntas ou interpretações à explicação do explicador. Há apenas a repetição da explicação que se encerra em si. É muito diferente da informação quando dosada, adequada para quem a ouve, simples, mas não simplista, tornando-se uma boa chave de leitura que se abre a novas conexões. Mas é preciso cuidado, pois o excesso de informação pode não deixar lugar à experiência. Alerta (Bondía, 2002, p. 22): "Não deixa de ser curiosa a intercambialidade entre os termos 'informação', 'conhecimento' e 'aprendizagem'. Como se conhecimento se desse sob o modo da informação e como se aprender não fosse outra coisa que adquirir e processar informação" (Martins, 2014, s/p.).

Assim, no programa de acessibilidade no qual atuei, como profissional e como pesquisadora, as ações cuidavam de servir uma dose equilibrada entre informação e experimentações ${ }^{6}$, para uma ativação das sensibilidades impregnadas na pele da vida. Em uma das exposições em que pesquisamos, "Obsessão Infinita" da artista japonesa Yayoi Kusama, havia uma instalação que criava em um espaço objetivamente pequeno, uma relação com o infinito através de espelhos nas paredes, um piso e alguns caminhos de água que refletiam as tantas luzinhas que faziam parte da instalação.

Era uma instalação completamente visual, que poderíamos usar de que maneira: descrevendo? Sim, claro... Dizendo o que ela produzia em quem via? Tam-

${ }^{6}$ Para uma boa discussão sobre a articulação entre experimentação e informação no campo da acessibilidade conferir Carijó, Magalhães \& Almeida (2012); Kastrup (2010); Vergara e Kastrup (2013). 
bém... Mas ficamos pensando... Só isso bastará para que as pessoas cegas, por exemplo, experimentem em seus próprios corpos, o infinito tratado por Kusama!

Entendendo que apenas a descrição desta instalação seria insuficiente para produzir um território fértil para uma experiência estética, os educadores propuseram, a partir dos conceitos da artista, uma Obsessão Infinita sonora. Nesse ponto é importante marcar que no grupo de educadores, estava eu, uma educadora cega - profissional e pesquisadora no campo da acessibilidade. Um dos objetivos da proposta de acessibilidade, pela via sonora, foi que antes que ela fosse experimentada pelo público que visitaria o espaço cultural, ela seria utilizada como ferramenta de capacitação dos próprios educadores, entre os quais, eu, pessoa cega.

E com o trabalho funcionou? Uma caixa de madeira quadrada, com uma porta que se fechava sempre que algum espectador entrasse. Dentro da caixa um microfone, um som e uma pedaleira de guitarra. Ao falar o que quisesse nesse microfone, a pedaleira fazia esse som existir por um bom e longo tempo. Por exemplo: se eu dissesse Camila, o som dizia: "Camila, Camila, Camila, Ca mi la, Caaa, miiii, laaaa, Caaaaaa, miiiiiii, laaaaa". Diferente do eco, a propagação não era somente dos finais das palavras, mas delas todas. Tínhamos ali uma relação com a profundidade, a repetição, o tamanho, que vinha pela força e perda de força do som. Neste trabalho, os conceitos da obra estavam sendo acionados por outra via, sem que precisássemos necessariamente, ou só, descrevê-la, reproduzi-la. É relevante dizer que era uma instalação aberta para todas as pessoas, com e sem deficiência e interessante para todos, inclusive para os que já tinham visto a instalação.

Com esse trabalho, a mediação constituiu-se como um campo expandido para as experiências estéticas, em que a conexão entre informação e experiência, não a escolha de uma em detrimento de outra, efetivou uma prática de mediação capaz de promover a acessibilidade na direção de uma experimentação estética.

Aqui se revela também a preocupação lidar com a mediação cultural não apenas como um modo de pensar sobre as relações entre sujeito e objeto de arte, mas sim ampliando a ação mediadora como uma proposição, uma criação. Proposições essas que, como diria Martins (2014), se ligam a ação do diálogo, da conversa e pressupõem a escuta, o espaço do silêncio, a aproximação cuidadosa e sensível com o outro.

\section{Por uma acessibilidade que deixe marcas: considerações finais}

As preparações das ações de acessibilidade num espaço cultural são como aquelas que fazemos em nossas casas para receber visitas. Passamos muito tempo nos preocupando com o que devemos fazer para arrumar o espaço para receber as visitas, mas corremos o risco de criarmos cenários de novelas, centros cirúrgicos, lugares menos vivos e assépticos.

O poeta Drummond (Andrade, 2002), no poema intitulado "Casa Arrumada", dá pistas importantes sobre esse processo. Seguindo suas considerações, ao nos preocuparmos em arrumar o espaço no qual recebemos nossas visitas, e no caso deste trabalho, as visitas das pessoas com alguma deficiência, devemos arrumá-los todos os dias, mas de um modo que possamos viver e nos (re)conhecer nesses espaços. A esta altura cada vez mais nos distanciamos dos modos de organização de um trabalho que se dá de forma estanque, fria, cirúrgica e nos aproximamos mais de um modo de fazer um trabalho que deixa marcas em quem está envolvido neste processo. Propomos um trabalho de acessibilidade que deixa marcas de copo na mesa, sofá manchado, arranhões no chão, que deixem visíveis os passos dançados. Uma acessibilidade capaz de deixar marcas seria uma acessibilidade capaz de produzir uma experiência sensorial estética. Mas o que seria então uma experiência sensorial estética?

Para Despret (2013), uma experiência sensorial acontece onde os organismos vivos se tocam, se afetam e estão sendo afetados uns pelos outros. Uma experiência sensorial, como sublinhado anteriormente, deixa marcas em quem está nela envolvido.

Podemos dizer que a experiência sensorial não é apenas uma perspectiva experimental que se pode inferir, ou mesmo compartilhar, de fora; não é apenas uma perspectiva que fundamenta a existência mesma de um sujeito, o sujeito desta perspectiva. A experiência sensorial acontece onde os organismos vivos se tocam, afetam e estão sendo afetados uns pelos outros. Reconhecemos uma experiência sensorial como a experiência concreta em que cada um dos que estão se "tornando atores" efetua nos outros o poder de ser afetados. Uma experiência sensorial é um fluxo de forças.

Como não existe uma maneira de tocar sem ser tocado, não há maneira de determinar quem toca quem. Tocar encena uma desubjetivação. Alguém pode agora ser agente sem ser um sujeito; não sendo, contudo, um objeto. Ser um sujeito é apenas um dos 
finais possíveis do processo - pode ser o fim que fecha a estória. Como Deleuze e Guattari (1995) escreveram em Mil Platôs, "é perigoso confinar-se a um tal assunto, que não funciona sem secar uma fonte ou parar um fluxo" (p. 68).

Atendíamos um grupo de pessoas cegas e com baixa visão. Todos vinham do Instituto Benjamin Constant, um instituto de referência nacional no atendimento de pessoas com deficiência visual. Este grupo vinha do setor de Reabilitação, setor que oferece uma série de atividades que tem como objetivo auxiliar na reorganização da vida das pessoas que adquiriram a cegueira na idade adulta. A exposição que acontecia na ocasião era Obsessão Infinita, da artista japonesa Yayoi Kusama. O grupo não conhecia o trabalho da artista até então. Começamos a visita dizendo que a artista trabalhava com pontos. A exposição tinha pontos por todos os lugares, desde as pinturas até as instalações. No final da primeira apresentação do que viria ser a exposição um integrante do grupo diz: Então é tudo braile!!! (Alves, 2016).

O relato desta visita traz a possibilidade de uma abertura nos significados dessa exposição. Somente esse grupo, com todas as suas singularidades, pode- ria ter dado à exposição um sentido que ela ainda não havia ganhado. É tudo braille, essa enunciação nem mesmo a Kusama havia dado para o seu trabalho. Este grupo transformou a visita a uma exposição de uma artista que na ocasião vinha recebendo muita atenção, inclusive da mídia, por conta de um sintoma, a sua obsessão. O que por muitos era visto como sintoma e patologia, tomando a sua produção artística como fuga para suas angústias, com o encontro com as pessoas cegas foi ganhando outros sentidos, sentidos próprios das experiências de vida daquelas pessoas. "É tudo braille": eis uma forma de experimentar a obra que transforma uma exposição, um mediador, uma visita. Deixa marcas, histórias, faz uma fonte continuar jorrando água, faz o fluxo seguir sua direção.

A experiência sensorial estética reinventa mundos, tornando-os mais densos, mais cheios de marcas e experiências. Uma experiência sensorial estética é coletiva, acontece no encontro com muitos, com muitas histórias. Cada coletivo torna mais densa uma exposição. A mediação é prática que envolve coletivos: de pessoas, obras, histórias, deficiências, capacidades. Levar adiante essas marcas é parte de nossa pesquisa e de nossa proposição de que a acessibilidade não seja levada adiante jamais sem contar COM as pessoas com deficiência, sem contar, em última instância, conosco.

\section{Referências}

Adichie, C. (2009). O perigo de uma única história. TEDGlobal 2009. Disponível em https://www.ted.com/talks/ chimamanda_adichie_the_danger_of_a_single_story?language=pt-br

Alves, C. A. (2016). E se experimentássemos mais? Um manual não técnico de acessibilidade em espaços culturais. (Dissertação de mestrado não publicada). Programa de Pós-graduação em Psicologia, Universidade Federal Fluminense, Niterói, RJ.

Andrade, C. D. (2002). Poesia completa. Rio de Janeiro, RJ: Nova Aguilar.

Anzaldúa, G., Marco, E., Costa, C. L., \& Schmidt, S. P. (2000). Falando em línguas: uma carta para as mulheres escritoras do terceiro mundo. Estudos Feministas, 8(1), 229-236.

Bondía, J. L. (2002). Notas sobre a experiência e o saber da experiência. Revista Brasileira de Educação, 19, 20-28. https://doi.org/10.1590/S1413-24782002000100003

Brum, E. (2010, 5 out.). Espelho, espelho não meu. Revista Época. Recuperado de http://revistaepoca.globo.com/ Revista/Epoca/0,,EMI181755-15230,00- ESPELHO+ESPELHO+NAO+MEU.html

Carijó, F., Magalhães, J., Almeida, M. C. (2012, 21 jul.). Acesso tátil: uma introdução a questão da acessibilidade estética para o público deficiente visual nos museus. In Sobre a deficiência visual. Recuperado de http://www. deficienciavisual.pt/txt-Acesso_tactil_DV_museus.htm

Conti, J. (2015). Contar histórias, povoar o mundo: versões de um encontro com a loucura e com a cegueira. (Dissertação de mestrado não publicada). Programa de Pós-graduação em Psicologia, Universidade Federal Fluminense, Niterói, RJ.

Coutinho, E., \& Bragança, F. (org.). (2008). Encontros: Eduardo Coutinho. Rio de Janeiro, RJ: Beco do Azougue Editorial. 
Deleuze, G., \& Guattari, F. (1995). Mil platôs: capitalismo e esquizofrenia (Vol. 5). Rio de Janeiro, RJ: Editora 34.

Despret, V. (2013). From secret agents to interagency. History and Theory, 52(4), 29-44. https://doi.org/10.1111/ hith.10686

Diniz, D. (2007). O que é deficiência. São Paulo, SP: Brasiliense.

Franco, L. (2016). Pensando a escrita no trabalho de pesquisa: por uma política da narratividade. Niterói, RJ: Eduff.

Haraway, D. (1995). Saberes localizados: a questão da ciência para o feminismo e o privilégio da perspectiva parcial. Cadernos Pagu, (5), 7-41.

Haraway, D. (2011). A partilha do sofrimento: relações instrumentais entre animais de laboratório e sua gente. Horizontes Antropológicos, 17(35), 27-64. https://doi.org/10.1590/S0104-71832011000100002

Honorato, C. (2012). Usos, sentidos e incidências da mediação: questões de Vocabulário. In: Anais do $21^{\circ}$ Encontro da Associação Nacional de Pesquisadores em Artes Plásticas, Rio de Janeiro, RJ. Recuperado de http://www.anpap. org.br/anais/2012/pdf/simposio5/cayo_honorato.pdf

Kastrup, V. (2010). Experiência estética para uma aprendizagem inventiva: notas sobre o acesso de pessoas cegas a museus. Informática na Educação: Teoria \& Prática, 13(2), 38-45. https://doi.org/10.22456/19821654.12463

Martins, B. S. (2006). E se eu fosse cego? Narrativas silenciadas da deficiência. Portugal: Afrontamento.

Martins, B. S. (2013). Pesquisa acadêmica e deficiência visual: resistências situadas, saberes partilhados. Benjamin Constant, 19, 55-66.

Martins, M. C. (2014). Mediações culturais e contaminações estéticas. Revista GEARTE, 1(3), 248-264. https:// doi. org/10.22456/2357-9854.52575

Mello, A. G. (2016). Deficiência, incapacidade e vulnerabilidade: do capacitismo ou a preeminência capacitista e biomédica do Comitê de Ética em Pesquisa da UFSC. Ciência \& Saúde Coletiva, 21(10), 3265-3276. https://doi. org/10.1590/1413-812320152110.07792016

Moraes, M. (2010). PesquisarCOM: política ontológica e deficiência visual. In M. Moraes, \& V. Kastrup. (Orgs.), Exercícios de ver e não ver: arte e pesquisa com pessoas com deficiência visual (26-51). Rio de Janeiro, RJ: Nau.

Moraes, M. (2011). Modos de ordenar eficiência e deficiência visual: breve leitura de um documento. Pesquisas $e$ Práticas Psicossociais, 6(1), 53-61.

Oiticica, H. (1981). Experimentar o experimental. Arte em Revista, 5, 50-52.

Rancière, J. (2010). A partilha do sensível: Estética e política. São Paulo, SP: Editora 34.

Santos, B. D. S., Brandão, G. M., \& Vianna, L. J. W. (2001). Por que pensar? Lua Nova: Revista de Cultura e Política, $54,11-42$.

Vergara, L. G., \& Kastrup, V. (2013). Zona de risco dos encontros multissensoriais: anotações éticas e estéticas sobre acessibilidade e mediações. Revista Trama Interdisciplinar, 4(1), 53-68.

\section{Camila Araújo Alves}

Psicóloga Clínica e pela Universidade Federal Fluminense (UFF), Niterói, - RJ. Brasil. Mestre em Psicologia pela UFF. Doutoranda do Programa de Pós-graduação em Psicologia da UFF. Psicoterapeuta Corporal e Docente do curso de Psicologia das Universidades Integradas Maria Thereza.

E-mail: camilaaraujoalves@yahoo.com.br

\section{Marcia Oliveira Moraes}

Professora Titular do Departamento de Psicologia da Universidade Federal Fluminense (UFF), Niterói, - RJ. Brasil. Docente permanente do Programa de Pós-graduação em Psicologia da UFF. Doutora em Psicologia pela Pontifícia Universidade Católica de São Paulo (PUC/SP), São Paulo - SP. Brasil. Financiamento de pesquisa: CNPq e Faperj. E-mail: marciamoraes@id.uff.br 
Psicologia: Ciência e Profissão Jul/Set. 2018 v. 38 n³, 584-594.

Endereço para envio de correspondência:

Universidade Federal Fluminense.

Campus Gragoatá, Bloco N - 4º andar, sala 417. CEP: 24210-201.

Niterói - RJ. Brasil.

Recebido: $02 / 07 / 2018$

Aprovado: 03/07/2018

Received:07/02/2018

Approved: 07/03/2018

Recibido: $02 / 07 / 2018$

Aceptado: 03/07/2018

Como citar: Alves, C. A., \& Moraes, M. (2018). Entre histórias e mediações: Um caminho para acessibilidade estética em espaços culturais. Psicologia: Ciência e Profissão, 38(3), 584-594. https://doi.org/10.1590/19823703000042018

How to cite: Alves, C. A., \& Moraes, M. (2018). Between stories and mediations: A path to aesthetic accessibility in cultural spaces. Psicologia: Ciência e Profissão, 38(3), 584-594. https://doi.org/10.1590/1982-3703000042018

Cómo citar: Alves, C. A., \& Moraes, M. (2018). Entre historias y mediaciones: Un camino para accesibilidad estética en espacios culturales. Psicologia: Ciência e Profissão, 38(3), 584-594. https://doi.org/10.1590/19823703000042018 